Revista Tecné, Episteme y Didaxis: TED. Año 2014, Número Extraordinario. ISSN Impreso: 0121-3814, ISSN web: 2323-0126

Memorias, Sexto Congreso Internacional sobre Formación de Profesores de Ciencias. 08 al 10 de octubre de 2014, Bogotá

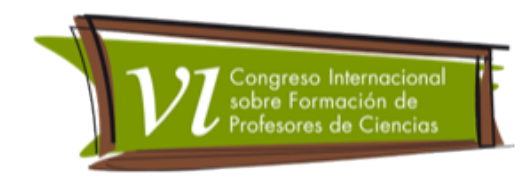

\title{
La investigación: un contenido relevante en la formación inicial de profesores de biología
}

Valbuena Ussa, Édgar Orlay', Castro Moreno, Julio Alejandro2, Hernández Pichardo, Análida Altagracia 3 , Vallejo Ovalle, Catalina ${ }^{4}$ y Trujillo Castro, Laura Marcela ${ }^{5}$

Categoría 2. Trabajo de investigación en proceso.

\section{Resumen}

Se presentan resultados parciales de la caracterización de la formación en investigación en ocho futuros profesores de Biología, vinculados a diferentes grupos de investigación. Los datos sistematizados se obtuvieron de cuestionarios, entrevistas, registro de participaciones en una plenaria y documentos (anteproyectos de trabajos de grado). Se encontró una diversidad de apreciaciones respecto al nivel de formación en investigación en el programa de Licenciatura en el programa de Licenciatura en Biología de la Universidad Pedagógica Nacional (Colombia).. En las propuestas de investigación de los docentes en formación, los problemas que predominan corresponden a la enseñanza de la Biología. Los futuros profesores explicitan la importancia de la formación en investigación como elemento potenciador de la profesión docente, además destacan la importancia de vincularse a grupos de investigación.

\section{Palabras clave}

Formación en investigación, futuros profesores de Biología, formación de profesores.

\footnotetext{
${ }^{1}$ Universidad Pedagógica Nacional (Colombia), Grupo Conocimiento Profesional del Profesor de Ciencias. valbuena@pedagogica.edu.co

2 Universidad Pedagógica Nacional (Colombia), Grupo Conocimiento Profesional del Profesor de Ciencias. alecasmor@yahoo.es

3 Universidad Pedagógica Nacional (Colombia), Grupo Conocimiento Profesional del Profesor de Ciencias. anaherpi@hotmail.com

Universidad Pedagógica Nacional (Colombia), Grupo Conocimiento Profesional del Profesor de Ciencias. mistica904 @gmail.com

5 Universidad Pedagógica Nacional (Colombia), Grupo Conocimiento Profesional del Profesor de Ciencias. Ialistruca75@hotmail.com
} 
Revista Tecné, Episteme y Didaxis: TED. Año 2014, Número Extraordinario. ISSN Impreso: 0121-3814, ISSN web: 2323-0126

Memorias, Sexto Congreso Internacional sobre Formación de Profesores de Ciencias. 08 al 10 de octubre de 2014, Bogotá

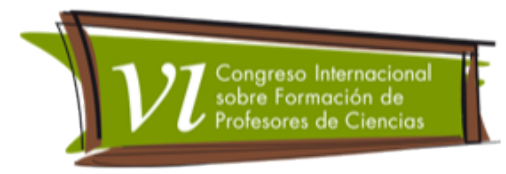

\section{Objetivo}

Esta ponencia hace parte del proyecto "Formación en investigación en futuros profesores de Biología", financiado por el Centro de Investigaciones de la Universidad Pedagógica Nacional (en adelante UPN), cuyo objetivo es contribuir a la caracterización de la formación en investigación en futuros profesores de Biología, al interior del Proyecto Curricular de Licenciatura en Biología de la UPN. Con la presente comunicación pretendemos específicamente caracterizar los referentes de investigación y formación en investigación de ocho futuros profesores en el marco del Seminario de Investigación.

\section{Marco teórico}

Al comparar los diferentes modelos de formación de profesores, se pueden evidenciar similitudes que permiten agruparlos en cuatro grandes tendencias: tradicionales (transmisionistas), tecnológicos, espontaneistas, de investigación y desarrollo profesional.

En cuanto a los Modelos de Investigación y Desarrollo Profesional proponen abordar la formación del profesorado desde el Conocimiento Profesional producido a partir de la reflexión en y para la práctica. Barnett y Hodson (2001), consideran que no basta con que el docente adquiera competencias para aplicar los referentes teóricos sino requiere, además, poseer un conocimiento tal que lo capacite para tomar decisiones en contextos educativos particulares. Lo cual justifica que en la formación inicial del profesorado se propicien espacios para que los futuros docentes vivencien los ambientes escolares, y reflexionen sobre las idiosincrasias particulares de los profesores en ejercicio y su incidencia en el ejercicio profesional. Se requiere acercar a los futuros profesores a las realidades cotidianas donde se ejerce la docencia, es decir, al contexto escolar. De acuerdo a Tardif (2004) bajo estos modelos en la formación inicial de profesores, se potencia el hecho de que éstos se reconozcan como sujetos de conocimiento docente y en esa idea se requiere que los estudiantes-profesores activen sus concepciones, intereses y experiencias. Imbernón (1998), plantea que es importante que el profesorado identifique áreas de interés, puntos de partida, de manera individual o grupal, de forma formal 0 informal, y realice investigaciones sobre su propia práctica. Bajo la perspectiva del profesorado como investigador de su práctica profesional, la investigación crítica en la acción y sobre la acción puede afianzar, desarrollar o modificar el Conocimiento Profesional, constituyéndose en un conocimiento de causa en diversas situaciones 
Revista Tecné, Episteme y Didaxis: TED. Año 2014, Número Extraordinario. ISSN Impreso: 0121-3814, ISSN web: 2323-0126

Memorias, Sexto Congreso Internacional sobre Formación de Profesores de Ciencias. 08 al 10 de octubre de 2014, Bogotá

particulares, y además puede considerarse como una actividad intelectual, una estructura de pensamiento que posibilita la conformación y el desarrollo de conceptos críticos sobre la educación.

\section{Metodología}

La perspectiva de esta investigación es cualitativa con enfoque interpretativo. Los datos se obtuvieron a partir de las declaraciones (cuestionarios, entrevistas y participaciones en una plenaria cuyo objeto de discusión fue la formación en investigación en el programa de Licenciatura en Biología de la UPN) de futuros profesores respecto a la investigación y a la formación en investigación al interior del programa de Licenciatura al cual están adscritos. Otra fuente de datos consistió en los anteproyectos de trabajo de grado formulados al interior del Seminario de Investigación (espacio académico previo al desarrollo del trabajo de grado).

La sistematización se hizo teniendo en cuenta el método de análisis de contenido, consistente fundamentalmente en el siguiente proceso: extracción de las unidades de información con sentido partir de cada una de las fuentes; agrupación de las unidades de información en las diferentes categorías de investigación; formulación de proposiciones para cada grupo de unidades de información; y análisis de las proposiciones (Valbuena, 2011).

La investigación se realizó con futuros Licenciados en Biología, al interior del Seminario de Investigación. Para efectos de esta ponencia se hace referencia al análisis realizado con ocho docentes en formación (codificados como E1, E2, E4, E5, E6, E7, E8 y E9), cada uno de los cuales ha estado vinculado a un grupo de investigación del Departamento de Biología de la UPN en el contexto de la práctica pedagógica.

La sistematización conllevó a la configuración de las categorías: Formación en investigación, proceso formativo (de investigación) en el programa de Licenciatura en Biología, aspectos institucionales (de la UPN respecto a la formación en investigación), y naturaleza de la investigación. En esta ponencia se hace referencia a la primera categoría. 
Revista Tecné, Episteme y Didaxis: TED. Año 2014, Número Extraordinario. ISSN Impreso: 0121-3814, ISSN web: 2323-0126

Memorias, Sexto Congreso Internacional sobre Formación de Profesores de Ciencias. 08 al 10 de octubre de 2014, Bogotá

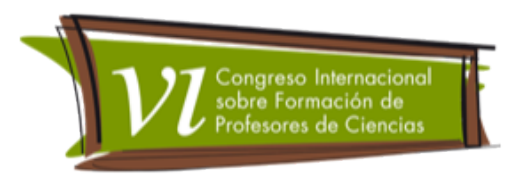

\section{Resultados}

Mayoritariamente, las propuestas de los futuros profesores tienen como objeto de investigación la enseñanza de la Biología (educación para la conservación de páramos, nutrición vegetal, saberes escolares de la Biología, enseñanza de la biodiversidad). A manera de ejemplo:

E1:...Resaltar la importancia del recurso hídrico para la vida y lo vivo posibilitando un cambio positivo de actitudes frente a la conservación del mismo... Diseñar actividades que faciliten la enseñanza-aprendizaje de algunas propiedades fisicoquímicas del agua...

En uno de los estudiantes se observa una tensión al manifestar una coexistencia de la investigación educativa y la investigación biológica (enfoque empiropositivista). Al referirse a su propuesta "Diseño de una Unidad didáctica para la enseñanza de los conceptos flavonoide y diterpeno a partir de un análisis fitoquímico de hojas senescentes de Croton funckianus (Euphorbiaceae)" expresa "... Entonces dentro de mi proyecto de grado, la parte disciplinar transportada a la parte pedagógica, yo tengo planteado el diseño de una unidad didáctica ¿̇Por qué? Porque el diseño de esa unidad didáctica lo que me va posibilitar es articular todos esos saberes disciplinares, botánicos y fitoquímicos, para yo poderlos enseñar a una comunidad en específico, ..." ; en esta cita se infiere la existencia de dicha tensión pues E9 asume que la Unidad Didáctica es un medio "para transportar" lo biológico a lo pedagógico al mismo tiempo que afirma que por este medio pretende "articular" dichos saberes.

En lo que atañe a la finalidad de la investigación como componente formativo de los futuros profesores, mayoritariamente destacan el rol de la investigación en la solución a problemáticas sociales de tal forma que se responda a necesidades propias de los contextos, como se evidencia en la intervención de E6: ... este proyecto busca implementar métodos de acercamientos a la comunidad educativa menos favorecida en la localidad de Bosa, para mejorar las carencias nutricionales de la población infantil; así, la finalidad de dicha propuesta es contribuir al mejoramiento de las condiciones de una población educativa, en especial de los hábitos alimenticios; para ello, E6 pretende diseñar una unidad didáctica, en la que pretende que padres de familia y niños conozcan mejor el valor nutricional de los alimentos que consumen. 
Revista Tecné, Episteme y Didaxis: TED. Año 2014, Número Extraordinario. ISSN Impreso: 0121-3814, ISSN web: 2323-0126

Memorias, Sexto Congreso Internacional sobre Formación de Profesores de Ciencias. 08 al 10 de octubre de 2014, Bogotá

De otra parte, relacionan la formación en investigación, con la constitución del maestro como sujeto.

E5: La investigación se convierte en un interés transversal para pensar al maestro, la enseñanza de la biología, las condiciones que actúan la biología en la escuela. Sin embargo también es un territorio del maestro para pensar y resistir, para crear, preguntar, cuestionarse pero también para trazar nuevas rutas pedagógicas.

Existe una diversidad de apreciaciones en los estudiantes respecto al nivel de formación en investigación al interior del programa de Licenciatura: ausencia, aproximación, transversalidad y realización de investigación sensu stricto.

Así, E2 y E6 consideran que no se realiza investigación, criticando que los ejercicios que se desarrollan en el Ciclo de Fundamentación de la carrera (I-VI semestres) e incluso en la práctica pedagógica (Ciclo de Profundización) se limitan a formular propuestas pero no se llevan a la práctica como investigación, identificando como limitante la falta de continuidad de las propuestas:

E2: ... que no sea solamente uno [un proyecto] para primer semestre, uno para segundo, uno para tercero; porque simplemente es presente objetivos, presente marco teórico y ya, ahí quedó. No! la idea sería un proyecto de primero, segundo semestre para que uno vaya cogiendo así como proceso y tratar de desarrollar ese mismo proyecto en todos los semestres para uno encontrar resultados, poder plantear sus mismas hipótesis, y no simplemente quede en el papel, ... sino, a mí me hubiera gustado en ese ámbito, coger un proyecto digamos de segundo semestre y desarrollarlo hasta llegar a un punto final que yo diga, bueno, todo este fue el proceso de mi carrera, un solo proyecto, y encontré todas estas problemáticas, todas estas conclusiones, análisis resultados, pero tengo una base sólida de un proyecto.

Por su parte Ely E8 manifiestan que en la Licenciatura realizan aproximaciones a la investigación; destacan además la importancia en dicho proceso de la vinculación a los grupos de investigación del Departamento de Biología:

El: Este proceso de práctica pedagógica ha estado apoyado por un seminario en el cual con ayuda del tutor se orienta el acercamiento a la investigación desde los referentes teóricos, metodológicos en educación. 
Revista Tecné, Episteme y Didaxis: TED. Año 2014, Número Extraordinario. ISSN Impreso: 0121-3814, ISSN web: 2323-0126

Memorias, Sexto Congreso Internacional sobre Formación de Profesores de Ciencias. 08 al 10 de octubre de 2014, Bogotá

Para E5 y E7, en la Licenciatura se realiza un proceso gradual y transversal en formación en investigación:

E7: "(...) la investigación la he visto en todos los espacios académicos ya que se manejan proyectos transversales que permiten acercamientos a la investigación. Aspectos como la consulta de documentos para relacionarlo con problemáticas cotidianas o que se observen en entornos en los que se esté inmerso.

En contraste, E4 y E9 consideran que en el programa de Licenciatura en Biología, como estudiantes realizan investigaciones propiamente dichas:

E9: Dentro de este ciclo, [de fundamentación] el maestro en formación, desde el trabajo en grupo hasta individual va adquiriendo herramientas, estrategias, procesos que le posibilitan asumirse como un sujeto investigador que piensa su accionar pedagógico o su profesión desde la incursión en los diferentes contextos educativos hasta de sus propias experiencias hasta la reflexión de su quehacer partiendo de preguntas que se llevan a cabo dentro de la contextualización o caracterización de donde se encuentre inmerso el sujeto maestro investigador.

\section{Conclusiones}

Existe una diversidad de apreciaciones respecto al nivel de formación en investigación en el programa de Licenciatura: ausencia, aproximación, transversalidad y realización de investigación sensu stricto.

En las propuestas de investigación de los docentes en formación, los problemas que predominan corresponden a la enseñanza de la Biología.

Los futuros profesores explicitan la importancia de la formación en investigación como elemento potenciador de la profesión docente.

La vinculación de los futuros licenciados a grupos de investigación facilita la formación en investigación.

\section{Referencias bibliográficas}

Barnett y Hodson (2001) Barnett, J. y Hodson, D. (2001). Pedagogical Context Knowledge: Toward a Fuller Understanding of What Good Science Teachers Know. Science Education, 85 (4), 426-453. 
Revista Tecné, Episteme y Didaxis: TED. Año 2014, Número Extraordinario. ISSN Impreso: 0121-3814, ISSN web: 2323-0126

Memorias, Sexto Congreso Internacional sobre Formación de Profesores de Ciencias. 08 al 10 de octubre de 2014, Bogotá

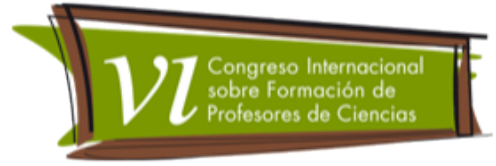

Imbernón, F. (1998). La formación y el desarrollo profesional del profesorado. Cuarta edición. Barcelona: Graó.

Tardif, M. (2004). Los saberes del docente y su desarrollo profesional. Traducción de Pablo Manzano. Madrid: Narcea

Valbuena, E. (2011). El análisis del contenido: De lo manifiesto a lo oculto. En: Páramo P. (compilador) La investigación en ciencias sociales: estrategias de investigación. Bogotá: Universidad Piloto de Colombia. pp 21 1-222. 